\title{
From Broker to Platform Business Models. A Case Study of Best Practices for Business Model Innovation in Hybrid Inter-Organizational Partnerships
}

\author{
Paula Ungureanu ${ }^{1}$ and Diego Maria Macri ${ }^{b}$ \\ ${ }^{a}$ Department of Sciences and Methods for Engineering (DISMI), University of Modena and \\ Reggio Emilia, Via Amendola 240122 Reggio Emilia, Italy paula.ungureanu@unimore.it \\ ${ }^{\mathrm{b}}$ Department of Sciences and Methods for Engineering (DISMI), University of Modena and \\ Reggio Emilia, Via Amendola 240122 Reggio Emilia, Italy dmacri@unimore.it
}

\begin{abstract}
This study is concerned with how hybrid partnerships -i.e., multi-party crosssector partnerships that deal with broad problems that go beyond the scope and scale of single partners- setup, implement and then innovate business models. In particular, we draw on a hybrid partnership for open innovation where six public and private organizations came together with the intention to setup and implement joint innovation projects with large scale impact at the regional level. Two business models of hybrid partnerships are discussed in this chapter, the brokering model and the platform model, as well as the mechanisms of transition from the first to the latter. Our findings suggest that while the platform model seems more appropriate for complex projects in which a wide number of heterogeneous interests coexist, both models present advantages and disadvantages. We suggest that attention should be given to considering advantages and disadvantages in a relational manner, by focusing on how the business model innovation will impact on each parameter of the current model and, at the same time, on how manageable the parameters of the new model are in terms of partnership strategy, structure and mobilizable resources.
\end{abstract}

Keywords: hybrid partnerships; cross-sector; broker; business model innovation; open innovation

\footnotetext{
${ }^{1}$ Corresponding author: Paula Ungureanu, email: paula.ungureanu@unimore.it
} 


\section{Introduction}

This chapter is concerned with business model innovation in cross-sector collaborations for complex innovation projects. Most research in business model innovation has focused on organizations' ability to create innovation and improvement processes in order to build new value propositions or enter new markets and industries (Massa and Tucci 2013) but less is known about what happens when business models need to be set up, assessed and revisited in a collaboration ecosystem with multiple private and public organizations, each mobilizing distinct interests, goals and objectives. We draw on a longitudinal case study of a hybrid partnership in the North of Italy that brought together multiple private and public actors such as the local government, a Chamber of Commerce, several industrial and trade associations, a Public Utility Company and a Regional European Development Office, with the goal to support open innovation projects at the regional level. The case study is particularly relevant for the Entrepreneurial, Innovative and Sustainable (EIS) ecosystem approach. In particular, it describes the birth and evolution of a local ecosystem focused on innovation, knowledge transfer and sustainability, in which heterogeneous organizations constantly stepped in and out of the boundaries of the project, according to their own interests and struggled, at the same time, to create an adequate business model for the ecosystem, which would have also reflected their own interests at hand. The case follows the evolution of a new organization called RIO that partners created in support of the partnership and to which they delegated the management of the partnership ecosystem. By following the evolution of RIO, we were able to trace the evolution of the ecosystem itself, identifying collaboration stages, critical turning points and best practices for managing the critical points of the partnership. In particular, we discuss three stages in the ecosystem: a brokering model stage, a transition stage and a platform model stage, and show how multiple adjustments were made from one stage to the next in order to suit more closely the nature and dynamics of the ecosystem. Unpacking the assumptions of each model, their critical points, the consequences and the coping mechanisms that they triggered, allowed us to adopt a practice-based perspective on business model innovation in hybrid partnerships. We propose a discussion on ecosystems organized according to brokering versus platform models. We suggest that a careful analysis of the characteristics of the ecosystem can favor the identification of best practices for its organization.

The chapter is organized as follows. We first discuss the importance of hybrid partnerships for open innovation. We then streamline what is known about business model innovation at the inter-organizational setting, and highlight a set of critical points that still need to be investigated to understand the challenges that setting up and modifying a business model at the inter-organizational level entails with respect to the organizational level. We then describe the context of the case study, and give an account of the main findings which are organized around three stages: the broker model stage, the transition stage and the platform model stage. In the discussion section, we summarize a series of advantages and disadvantages of the two models, 
and comment on how they inform best practices about business model innovation in the case of hybrid partnerships.

\section{Towards an understanding of business model innovation in hybrid partner- ships}

\section{1 - Hybrid partnerships as tools for open innovation}

Inter-organizational collaborative activities have become more prominent and extensive not just in the private sector but in the public sector as well, with hybrid forms of collaborative engagement between business, government, and civil society being stipulated every day (Bryson et al. 2006; Hartley et al. 2013; Kivleniece and Quelin 2012; Selsky and Parker 2005). Many of these cross-sector collaborations are constituted to address metaproblems - broadly defined overarching frames entailing interests that have to do with the public good and go beyond the jurisdiction and competencies of single organizations. Examples of metaproblems addressed through public-private collaborations are fostering industrial competitiveness, managing urban development, improving social welfare and fostering social innovation, or programming the sustainable development of a given region (Linder and Rosenau 2000; Selsky and Parker 2005).

A case that entails significant challenges is that of cross-sector partnerships for collaborative (i.e., open) innovation where public and private organizations get together with the intention to setup and implement joint innovation projects with large scale impact. As far as the public sector is concerned, there has been growing attention to intrapreneurial and entrepreneurial processes (Damanpour and Schneider 2009; Leitao and Alves 2016; Morris \& Jones 1999). For instance, trends in public entrepreneurship are increasingly pushing public actors towards innovation ecosystems that encompass cross-cutting organizations, groups, teams and communities (Bernier and Hafsi 2007; Hjorth 2013). Accordingly, not only governments become interested in promoting and supporting the innovation of private organizations but they also turn into active project stakeholders. Motivations include expanding jurisdiction to new sectors by retrieving skills and competencies that are not available internally, achieving legitimation in new markets and fields, or simply adjusting to the institutional logics of the New Public Management (Bryson et al. 2006; Skelcher 2005). Similarly, private organizations that try to enter fields and markets where private initiative is viewed with suspicion are increasingly considering long-term partnerships with public organizations, governmental institutions or NGOs (Googins and Rochlin 2000; Rondinelli and London 2003). By lowering costs, reaching new groups of customers, and more broadly filling institutional voids through new product or service offerings, open innovation is considered a tool to create bundles of social and economic value (Koschmann et al. 2010; Le Ber and Branzei 2009; Selsky and Parker 2005). As a consequence, it becomes important to understand how organizations engaged in long term cross-sector multi-party part- 
nerships manage to collaborate inside complex innovation projects and, in particular, how they setup, negotiate, implement and revisit the business model of the partnership throughout its lifecycle.

It has been argued that ecosystems that entail heterogeneous partners present multiple challenges for those who enact them. For instance, there is evidence that although collaboration between cross-sector organizations mobilizes broadly defined objectives as to allow partners' divergent interests to co-exist, collaborations are often permeated by tensions between self versus common interest, especially as the number of partners increases (Turcotte and Pasquero 2001; Waddell and Brown 1997). It is thus important to understand the main advantages and challenges faced by public and private organizations that decide to collaborate in complex innovation projects. More importantly, it is important to keep track of how the partnership evolves through time. The creation of a common ground for collaboration has been said to play a fundamental part in partnerships' ability to adjust through time (Majchrzak et al. 2015). Koschmann and colleagues (2010) have argued, for instance, that the overall value of cross-sector partnerships is not merely in connecting interested parties but, rather, in their ability to substantially influence the people and issues within the domains of the interested parties. This ability, they argue, comes from the constitution of organizational forms that are distinct from their members and that display collective agency - the capacity to influence a host of relevant outcomes beyond what individual organizations could do on their own. New structures such as functional roles, organizational teams, common projects and common goal structures have been found useful for negotiating tensions and fueling partnership interaction because they can act as scaffolds for the creation of a common ground (Doz and Baburoglu 2000; Le Ber and Branzei 2009). On the one hand, attempts to create a common strategy allows actors to draft premises and rules of the game, but on the other, given the different interests and logics at stake, it paves the way for additional conflicts and misunderstandings that organizations might not be prepared for upfront (Selsky and Parker 2005; Turcotte and Pasquero 2001). We thus argue that business models, and partners' ability to setup, negotiate and revise business models (i.e., business model innovation) may play a fundamental role in understanding, diagnosing and establishing best practices for the evolution of hybrid partnerships through time.

\section{2 - Business model innovation in hybrid interorganizational partnerships}

Although no generally accepted definition of the term "business model" has yet been reached -for instance, terms such as "business model", "business strategy" or even "economic model" are often used interchangeably (Morris et al. 2005)- business models reflect "management's hypothesis about what customers want, how they want it and what they will pay, and how an enterprise can organize to best meet customer needs, and get paid well for doing so" (Teece 2010 p.20). In other words, 
business models offer a holistic approach explaining how firms "do business" encompassing basic insights of innovation, business processes and routines (Casadesús-Masanell and Ricart 2010; Cavalcante et al. 2011; Zott et al. 2011). A good business model is a relatively comprehensive description of the organization's situation, structures and capabilities, the partners, the target market, the value proposition, who is creating and capturing value, the value chain, as well as which activities will be conducted by the focal firm, by partners, or through arm's length transactions, as well as revenue and cost structures. It is important to note that a business model will include not just a description of the organization but also, critically, a description of its environment, including the broader (economic, social and political) institutional context, competitors, customers, consumers, suppliers and especially relevant for our discussion - partners (Dahan et al. 2010).

According to extant research, both the design of business models and the ability to constantly introduce innovations to the business model are key issues for any organization looking for better performance and higher value capture. In literature, this has been discussed under the name of business model innovation (BMI) (Amit and Zott 2012; Chesbrough 2010; Mitchell and Coles 2003). Accordingly, BMI is associated to the ability to create innovation and improvement processes at the firm level that can be used to build new value propositions or enter new markets and industries. Adding new firm activities, linking existing activities in new ways or changing their distribution inside the firm have been all discussed as relevant BMI processes (Massa and Tucci 2013).

While most research has been concerned with business model innovation at the firm level, there is still little understanding of the challenges of first setting up, and further on innovating the business models of hybrid inter-organizational partnerships (Chesbrough and Scwartz 2007; Dahan et al. 2010). Studies suggest that a main factor to shape the developmental path of an alliance is partners' ability to first assess and then react to discrepancies between initial and emergent conditions (Arino and de la Torre 1998; Eden and Huxham 2001; Le Ber and Branzei 2009; Majchrzak et al. 2015). It is interesting to point out that in many of the cases in which cross-sector partnerships are set up, there is no pre-established business model, such that in some cases partners use a business model of one of the partnering firms that they gradually modify and adjust to reflect the logics and functioning of the entire partnership or, most commonly, they build a business model from scratch (Dahan et al. 2010). From such standpoint, creating a business model for a cross-sector partnership is a step-by-step, trial and error project which might have important consequences for the trajectory of the partnership and the dynamics between partners. From such standpoint, it is thus important to define a list of does and don'ts for those who are considering engaging in such projects, and outline critical points in the adoption and use of partnership business models (Bryson et al. 2015).

\section{Context description}


In this chapter, we draw on a multiple-year case study of a hybrid collaboration in Italy between one Municipality, one public University, three trade and industrial associations, one Chamber of Commerce, a Public Utility Company and a Regional European Development Office that came together with the broad goal of supporting innovation and knowledge exchange at the regional level. The E.U. Cohesion Policy has been supporting for many years cross-sector collaborations between government, universities and the private sector to deliver innovation in E.U. regions (CEC 2014), and Italian regions have been no exception to this trend. For instance, not only is strengthening research, technological development and innovation singled out in the E.U. Cohesion Policy for 2014-2020 as a leading way to generate "smart specialization" across European regions, but also highly prioritized by the long-term strategies of Italian local governments (Romano et al. 2014; Zerbinati and Souitaris 2005).

In line with the institutional context in which it was inserted, the partnership that we studied was founded in 2009 in support of open projects for local innovation. To this purpose, stakeholders signed an Innovation Agreement in which they committed to "join resources to obtain mutual benefits related to innovation and knowledge transfer" by putting together "an innovative local government", "highly competitive industrial region" and "distinctive research competencies of the local University" (cfr.). Following the Agreement, a new organization was created - the Regional Innovation Office (RIO) which had the purpose to implement the partnership agenda. This implied identifying concrete market opportunities for shareholders' innovation projects, managing innovation projects on behalf of the shareholders, and negotiating, throughout the process, their heterogeneous goals and interests. By studying the evolution of RIO from its foundation to the present date, we trace the evolution pattern of the partnership and identify a series of critical points which have determined partners to reconsider the initial business model of the partnership as to move towards more customized and at the same time enabling business models.

\section{Main findings}

The case study describes three stages in the evolution of RIO: the broker stage, the transition stage and the platform stage, emphasizing how the shortcomings of the first business model and the subsequent threat of partnership failure in the transition stage have led to the setup of the second model. The setup of the platform model will be here proposed as best practice for collaborations between (multiparty, cross-sector) private institutions with highly diversified and heterogeneous interests, and a set of trade-offs with respect to the broker model will also be identified.

\section{1 - The broker model stage}


4.1.1 Assumptions: In the first phase of the collaboration (2009-2014), RIO was designed as broker -as a boundary organization that was expected to collect, assemble and enact the multiple interests of its shareholders. Since partners had collaborated only occasionally and predominantly in dyads but never around long-term projects and never together in formalized partnerships, they had little knowledge of each other's goals and interests, and even less understanding about how to interconnect them. As a consequence, all participating institutions expressed the intention to create a broker that would mediate inter-organizational differences and contribute to the creation of a dense network of inter-organizational actors, resources and projects. Besides, since partners felt the pressure to act as a whole, they expected RIO to scout, manage and carry out projects on their behalf. At the end of this timespan, RIO traversed financial and legitimacy crises, mostly due to partners' reluctance to make further investments. As time passed, RIO started being perceived as a third party, a boundary organization that no longer represented their interests. In particular, partners' intention to delegate to RIO all aspects of managing the partnership, on the one hand, and their unwillingness to give up control, on the other hand, generated an environment full of contradictions, ambiguities, malfunctions and unexpected events. Figure 1 represents graphically the assumptions of the brokering model.

Fig. 1. EIS ecosystem with brokering model

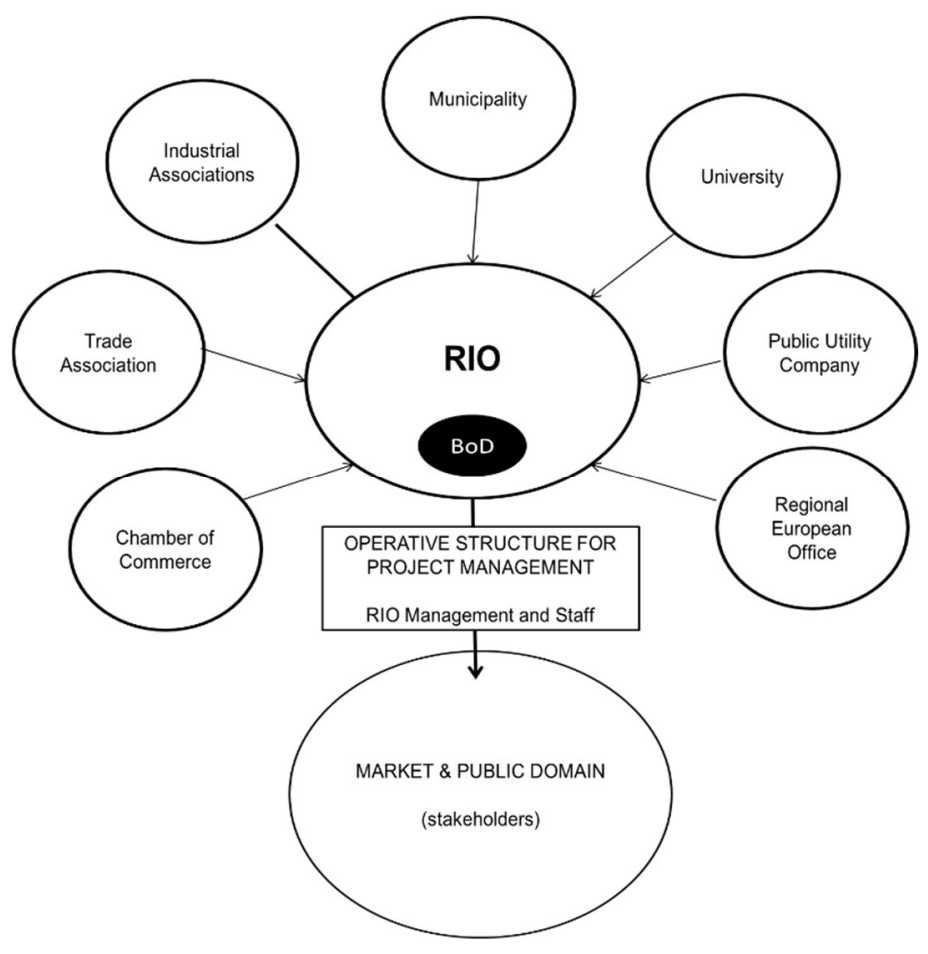


4.1.2 Shortcomings: Several factors concurred to the fact that, as time passed, RIO started to be perceived as a third party, a boundary agent that did not represent shareholders' interests:

1. Overflowing goals: Partners were animated by different goals that proliferated in uncontrollable ways. ${ }^{2}$ Since these goals were manifold and highly specific, partners continued to pursue them individually or in dyads despite the partnership frame. As a consequence, RIO's assignment remained excessively broad and generic.

2. Split hierarchy: RIO was assigned the responsibility to coordinate common projects but not also the authority to do it. Each organization continued to run decision making processes internally.

3. Double unaccountability: RIO was evaluated each year based on a generic mission of "innovation and technological transfer", rather than on specific projects or on well-defined goals assigned to each project. This was motivated by partners' will to ensure that RIO had enough autonomy and flexibility on the market, on the one hand, but also by their intention to avoid direct responsibility for joint projects. The double unaccountability loop had led, on the one hand, to partners' perception that RIO was not generating value for their organizations and for the public domain in general, and, on the other hand, enhanced RIO's belief in founders' lack of interest and responsibility.

4. Opportunistic behavior: Actors either did not delegate their projects to RIO or decided to opportunistically delegate those projects with scarce resources or with limited internal support.

5. Marginal assignments: Most of the projects that the partner organizations delegated to RIO were not concerned with their core activities but with marginal activities. These were either activities that partners felt comfortable sharing with outsiders because they were not strategic for their organizations, either activities that did not count significantly towards the organizational performances, or activities for which they did not have internal funding or support.

${ }^{2}$ To give an example, the Municipality was concerned with urban development, social welfare and cultural initiatives, the University with obtaining new research funding, the Chamber of Commerce was interested in legitimating its choices for allocation of public funds, the Public Utility Company was concerned with a specific urban regeneration project, the European Office aimed at implementing a network of science parks across the region, and the trade and industrial associations were animated by the need to defend the interests of the firms they represented, and their own interests as well (e.g., competition and collaboration with other industrial associations). 
6. Limited entrepreneurial initiative: RIO only rarely manifested initiatives such as proposing new projects or creating new opportunities for its stakeholders. RIO attributed the limited entrepreneurial initiative to the scarce resources and the limited institutional legitimation that partners invested them with.

7. Decreasing investments: Shareholder's financial investment in RIO was limited, and diminished each year. This was also reinforced by the perception that RIO was not generating value.

8. Information gaps: RIO and its stakeholders had limited information about each other's projects, initiatives, goals and activities. The communication system was deemed insufficient by all parties. It mostly ran through RIO's informal relations and largely depended on RIO's ability to use informal relations with each of the partnering organizations. However, the flow of projects, plans, objectives and expectations that each partner brought to the partnership was much more than RIO's organizational structure could process.

\section{2 - The transition stage}

The 2014-2015 timespan marked a critical stage of transition. In particular, after the implementation of the brokering model and the first dissatisfactions with the model, RIO traversed a period of financial and legitimacy crisis. The Municipality, the University and the Chamber of Commerce saw their institutional roles altered by national legislation changes. The difficulties faced by these organizations in committing to the collaboration project on the long term, together with the perception of RIO's inability to generate value for each single partner, determined partners to inquire about whether maintaining or terminating the partnership. This caused a period of paralysis as far as decision making about existing projects, and launch of new projects is concerned. After a long and hurdled period of transition, partners decided to keep the partnership alive and to restructure RIO according to a new model that would reflect more closely their specific needs and interests. We identified several reasons that contributed to this decision:

1. Pressures to avoid partnership failure: Manifold institutional pressures for legitimation and accountability prevented partners from declaring the failure of the partnership. Since stakeholders were inserted in a natural ecosystem in which they co-existed (i.e., the region), the failure of the partnership was perceived as a potential threat for the public domain -a "point of no return" in the evolution of the local community. As a consequence, partners were motivated to avoid breakpoints at all costs.

2. Persistence of collaboration goals: Just as in 2009 when they had decided to found RIO, partners still had the pressing need to engage in innovative collaborations with other institutions as to generate more value for themselves and for the local community. Accordingly, during the transition phase the leaders of the partnering organizations had come to believe that 
the complex activities of the partnership could have been only dealt with by persevering in the project of collaboration.

3. Compulsion to complete the collaboration infrastructure. Despite rising conflicts, tensions and mistrust, partners evaluated they were halfway in the realization of a common structure to enable open innovation. As such, delegating the management of the partnership to a boundary organization such as RIO was still considered the best, if not the only possible solution. However, there was considerable confusion about how the project could have been restructured as to avoid the traps experienced in the first phase, and to overcome the paralysis that characterized the second phase.

\section{3 - The platform model stage}

4.3.1. Assumptions: All the organizations that had initially founded RIO decided to preserve the partnership and to restructure RIO according to a new model that would have reflected more closely their specific needs and interests. Starting with the second half of 2015, partners engaged in a one-year consultation process aimed at reorganizing the business model of RIO. This process reconsidered the relational and instrumental structure of the partnership, from goal setting and authority settlements, to resource allocation and levels of commitment. The platform was designed, prototyped and is currently being experimented, as follows:

1. Loosely coupling heterogeneous interests within a multi-layered platform RIO was transformed from a boundary organization that operated on the market with the mandate of its shareholders to a boundary-less organization that coopted projects from a large number of local stakeholders. To this purpose, RIO encourages not only its shareholders, but also other local shareholders interested in open innovation, to launch projects of interest and to lobby those projects to other organizations, in the attempt to obtain necessary resources to take the project further.

2. Concentrating governance and widening participation: Partners decided to reduce the shareholders base in order to concentrate authority, responsibility and decision making inside a circumscribed perimeter. Moreover, they redesigned the Board of Directors to give voice to the top management of the partnering organizations (Mayor, University Dean, Presidents of Industrial Associations, President of Public Utility Company, President of European Regional Agency and President of RIO). This also contributed to the creation of an informal circle of decision makers in the ecosystem. Whereas the shareholders' base, the stakeholders base was widened in order to attract as many resources as possible, to encourage diffusion of the partnerships' initiatives, and to gain legitimacy in the local community.

3. Disintermediating: Rather than delegating projects to RIO, the stakeholders are encouraged to launch the projects themselves. A project must be launched by a triggering organization/institution that manifests a strong interest in a project which requires collaboration with other organizations 
and/or institutions (e.g., setting up a regional science park, creating a joint industry-academia $\mathrm{PhD}$, designing a national database on technology transfer projects). With the help of RIO, the triggering actor identifies and mobilizes relevant partners.

4. Abolishing generic missions: RIO's old mission regarding generic activities of innovation and knowledge transfer was abolished. Instead, its action became the direct expression of stakeholders' interests.

5. Creating project units: Each project constitutes a separate organizational structure which is designed, managed and evaluated only by those organizations that manifest a direct interest in its realization. These structures received the name of "innovation units". Innovation units are characterized by juridical and financial autonomy -i.e., they constitute as separate organizational units inside RIO, or even as separate firms within the firm. Their responsibilities include defining the purpose of the project, clarifying goals and sub-goals, budgeting the project activities, and composing project management teams.

6. Managing a multi-layered platform: In the platform model, the main mission of RIO is the coordination of the platform. First, RIO is responsible for providing a set of basic services to the innovation units (physical space, administrative staff, communication, etc.). Second, RIO develops a service catalogue from which each innovation unit can choose the services of interest (e.g., project management, legal support, public relations, funding proposal drafting, etc.). This allows to create a personalized offer according to the contextualized needs of each unit. While for the basic services a fixed cost is imputed to RIO's shareholders on an annual basis, for catalogue services costs are assigned to each innovation unit (thus to stakeholders) by perceiving a service fee with variable percentages to be defined at the moment of creation of the innovation unit. Such services are delivered by RIO in collaboration with a pool of external collaborators -consulting firms, professionals and freelancers, etc. Services that are not contemplated in the catalogue might also be offered to innovation unit,s provided the renegotiation of the annual fee.

7. Mobilizing network externalities: In addition to managing the ecosystem of innovation units, RIO has the mission of creating synergies between innovation units, scouting for new resources, encouraging new entrances and anticipating exits, managing the overall portfolio of innovation units, and planning its short and long-term evolution.

8. Building communication and reporting infrastructures. RIO also plays an active role in facilitating information flows inside, across and outside the innovation units. Each innovation unit communicates the evolution of the project to RIO management. In turn the latter documents the composition and evolution of the platform's projects portfolio, reporting results to the BoD and to the Platform's Scientific Committee. The latter is composed of scientists, influent managers and technology gurus that are responsible for 
identifying general technological innovation trends in the market and studying their compatibility with the platform's features and requirements.

Figure 2 below represents graphically the assumptions of the platform model, as described in the eight points above.

Fig. 2. EIS ecosystem with platform model.

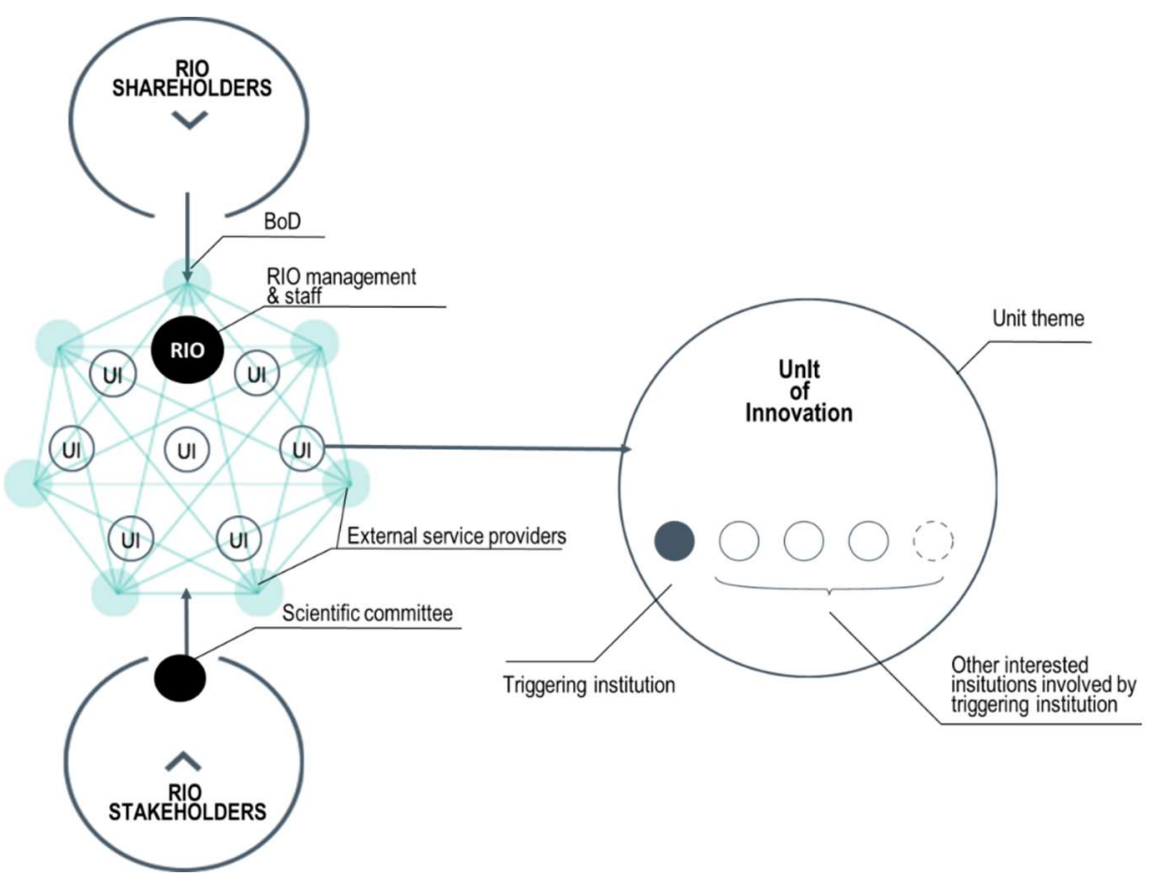

\section{Discussion and implications for practice}

Although it has become almost commonplace to think about public and private organizations in open innovation systems, it has been less straightforward to think that such initiatives can assume various forms -especially when they imply collaboration with other organizations. It is also important to consider that such forms are highly dependent on the characteristics of the environments in which they develop, and that different partnership business models can lead to different partnership configurations, and different partnership outcomes (see also Clodia Vurro et al. 2010).

A paradox of cross-sector partnerships is that by which partnering organizations might designate brokers to accomplish innovation activities on their behalf rather than act as innovators themselves. Table 1 summarizes the characteristics of the EIS 
ecosystem and shows their consequences when a broker model or a platform model are adopted. By comparing the brokering model with the platform model, it becomes visible that the latter was established to answer shortcomings experienced with the first. Specifically, setting up brokerage units to which organizations broadly delegate the responsibility of managing complex inter-organizational projects has become a common practice. The complexity of the partnership objectives, the uncertainty of its long-term outcomes and the difficulty of negotiating heterogeneous interests, among others, are some of the reasons why partnerships might opt for a brokering model.

Table 1. Characteristics of the EIS ecosystem and consequences for the adoption of brokering and platform models

\begin{tabular}{|c|c|c|}
\hline Characteristics of EIS ecosystem & Brokering model & Platform model \\
\hline 1. Heterogeneous goals & Overflowing goals & $\begin{array}{l}\text { Loosely coupling hetero- } \\
\text { geneous interests within } \\
\text { a platform }\end{array}$ \\
\hline $\begin{array}{l}\text { 2. Multiple individual governance systems } \\
\text { and common governance systems run in par- } \\
\text { allel (e.g., RIO BoD) }\end{array}$ & Split hierarchy & $\begin{array}{l}\text { Concentrating govern- } \\
\text { ance \& widening partici- } \\
\text { pation }\end{array}$ \\
\hline $\begin{array}{l}\text { 3. Responsibilities are dispersed in the net- } \\
\text { work }\end{array}$ & Double unaccountability & Disintermediating \\
\hline $\begin{array}{l}\text { 4. Collaboration goals and sub-goals are } \\
\text { broadly defined and highly inclusive }\end{array}$ & $\begin{array}{l}\text { Opportunistic behavior } \\
\text { related to generic mis- } \\
\text { sions }\end{array}$ & $\begin{array}{l}\text { Abolishing generic mis- } \\
\text { sions }\end{array}$ \\
\hline $\begin{array}{l}\text { 5. Priorities are assigned differently by net- } \\
\text { work organizations according to internal sys- } \\
\text { tems of relevance and modify over time }\end{array}$ & Marginal assignments & Defining project units \\
\hline $\begin{array}{l}\text { 6. Initiatives are born spontaneously and go } \\
\text { extinct spontaneously, as actors interact in the } \\
\text { ecosystem }\end{array}$ & $\begin{array}{l}\text { Limited entrepreneurial } \\
\text { initiative }\end{array}$ & $\begin{array}{l}\text { Managing the multi-lay- } \\
\text { ered platform }\end{array}$ \\
\hline $\begin{array}{l}\text { 7. The growth of the ecosystem depends on } \\
\text { the extent to which actors allocate and mobi- } \\
\text { lize resources across boundaries }\end{array}$ & Decreasing investments & $\begin{array}{l}\text { Mobilizing network ex- } \\
\text { ternalities }\end{array}$ \\
\hline $\begin{array}{l}\text { 8. Information flows fast, asymmetrically, } \\
\text { and unpredictably }\end{array}$ & $\begin{array}{l}\text { Lack of shared infor- } \\
\text { mation }\end{array}$ & $\begin{array}{l}\text { Creating communication } \\
\text { and reporting infrastruc- } \\
\text { tures }\end{array}$ \\
\hline
\end{tabular}

As summarized in Table 1 and described throughout the case study, the adoption of a brokering business model can generate a sort of ambidexterity in the partnership such that the partnering organizations (i.e., the partnership shareholders) remain focused on their core missions and, at the same time, create boundary organizations 
that operate on their behalf in new fields of interests. We have exemplified some of the reasons why the brokering model has high likelihood of failure in cross-sector partnerships. This does not mean that the brokering model is destined to fail in any situation but that in the environmental conditions here described (see Table 1), only difficultly could have partners' goodwill and best practices avoided the failure of the model. We do not imply that there are no examples of boundary organizations that use the brokering model successfully to deal with complex innovation projects. Instead, we suggest that although brokering organizations operate with success in different sectors of the private and public economy, the likelihood that these units reach the goals for which they were created decreases as the number and the heterogeneity of the goals assigned to them increases (see Bryson et al 2006; Lunnan \& Haugland 2008). Furthermore, the circumscribed nature of brokering models renders them less subject to exponential growth than platform models: While in the brokering model partners assigned to RIO a general mission of innovation and technological transfer which in turn RIO had to first articulate and then implement according to its own understanding and competencies, in the platform model a higher number of actors played a more active role.

What is interesting to notice is that even if both the platform model and brokering model were designed to meet their interests, partnering organizations were more willing to mobilize resources within innovation units than they were willing to assign them to RIO during the brokering years. This is also connected to the risk that partners may reach a certain point in which they perceive the broker as a third party that is not the expression of their strategic vision, either as single organizations or as partnership. If allocating resources to RIO is perceived in the first case as a contribution to a higher (and more generic) goal, in the latter it is seen as an investment in a strategic project for one's organization. To give an example, in Italy, the brokering model is mostly used by single organizations or by bipartite partnerships to setup complex projects with external stakeholders (e.g., Universities that setup independent organizations to deal with industry relations, Municipalities that create independent organizations to deal with local fundraising for public innovation, private firms that create a task force for social innovation projects, etc.). These projects still represent a very small fraction of the total expenditure in research and development of Italian public and private organizations, but they are on the rise, just as the hybrid multi-stakeholder project that we have presented in this study (see Muscio 2010). Our findings suggest that while brokering organizations with few shareholders can thrive by hyper-specializing in a set of goals that their shareholders have in common, this is not applicable to brokering organizations that are accountable for broad and potentially divergent goals pertaining to a high number of shareholders from different sectors. The risks that we emphasized in this case study are distributed across a continuum that goes from difficulties to negotiate heterogeneous goals, on the one hand, to the tendency to establish overarching goals that are broad enough to encompass shareholders' divergent interests, on the one hand, but also ambiguous enough to be misrecognized by them, on the other hand (see overflowing goals). 
Another important risk is the difficulty that brokering organizations encounter in maintaining both authority and responsibility on the goals assigned to them by shareholders (see split hierarchy and unaccountability), as well as maintaining shareholders' commitment to financing their activities (see opportunistic behavior, marginal assignments and decreasing investments). In particular, we have shown that the difficulty to capture investments might determine brokering organizations to spend more time looking for shareholders' financial support than reaching the objectives assigned to them. This, in turn, impacts negatively on their image, and on the perception that they can generate value for the shareholders and for the community of stakeholders at large.

The platform model overcomes such problems because it gives space to public institutions, businesses and other social institutions to come together directly, without intermediation. The Units of Innovation (UI) here described represent self-determined groups that, by making use of the supportive functions of the platform, collaborate to carry forward projects of direct concern for shareholders. When a cross-sector partnership becomes organized like an open platform, the boundaries between shareholders and stakeholders (interested individuals, organizations or communities that are situated outside the partnership) become blurred. The UI can be thus seen as small businesses that plan, finance, implement, promote and monitor projects of direct concern but which have the particularity that their members represent both the innovation unit and the partnering organizations. Then what matters is that the parties that create an innovation unit maintain full control on goal setting, resource allocation and project implementation, regardless of their more or less stable affiliation with the partnership. Since the destiny of the UI depends directly on their efforts, they must act as entrepreneurs, actively looking for support for the innovation unit, rather than delegating to the broker. In other words, the previously mentioned paradox is resolved such that organizations no longer delegate broad objectives but work with other interested parties to select and make them come to life. Needless to say, this can also trigger some negative consequences, such as the increasing complexity that involved parties confront with inside and outside the partnership, scarcity of competent resources, or tendency to stabilize some coalitions in order to lower the complexity of managing a highly diverse portfolio of innovation units. Another particularity of the platform business model is that by emphasizing the active roles of the partnering organization, the role of the brokering organization becomes one of technical support. While this may appear like a downgrade, it actually deals more realistically with what a small organization can do for a high number of partners which manifest little willingness to make large investments in joint projects of uncertain outcomes. As we have seen, precisely because of the uncertain outcomes that a collaboration with diverse stakeholders will bring for each of the involved parties, actors may feel entitled to push their own goals in the partnership agenda and show reluctance in delegating the control over partnership decisions (see also Austin and Seitanidi 2012). 
It is important to notice that in addition to the abolishment of the generic mission and to disintermediation, another fundamental advantage provided by the platform model has to do with the capacity to mobilize network externalities. While in the broker model the brokering organization is responsible for finding resources and assembling them around specific shareholder interests, in the platform model the boundary organization has a mere support role, identifying synergies between projects and suggesting more efficient recombination across innovation units. Yet, as stressed earlier, it is the innovation unit that maintains at all times full responsibility for making the project grow -i.e., creating connections with other potential interested parties and promoting projects to the community at large. The brokering organization can offer a broad range of services in support of these activities but only if the members of the innovation unit have clearly indicated the nature and direction of their needs. From this standpoint, the boundary organization acts as a warranty for the rationalization of the activities hosted on the platform, creating communication and reporting infrastructures inside and across units of innovation. Most importantly, the brokering organization in the platform model identifies synergies and establishes a strategic direction to ensure the growth of the platform over time, on the one hand, and the reinforcement of its identity, on the other.

We would like to point out that the platform model is not without flaws and risks. First, the flow on the platform depends heavily on the strength of the entrepreneurial interests of the partnering organizations. Second, it depends on their ability to attract the interests of other actors inside and outside the partnership as to create functioning and autonomous innovation units. In the absence of these conditions, the network becomes less dense, and the ability to mobilize network externalities also becomes more modest. The network effect in the platform model is highly important because the main advantages of participating to an innovation platform derive not so much from the services provided by the boundary organization, but from the opportunities arising from complex networks of social and economic interests (see Koschmann et al. 2010). Most importantly, innovation units are also difficult to manage because they entail actors with different backgrounds and partially divergent objectives. The management of such units can provide significant challenges for partners and for members of the brokering organizations who are called to act as facilitators. Although this last aspect has received less attention both in research and in practice, it is particularly important to set up appropriate infrastructures in support of the professionalization of boundary brokers, such as training offers, policy guidelines or access to existing best practices (Hundal 2014; Jupp 2000; Warner 2003).

Another key aspect for understanding business model innovation in cross-sector partnerships is the transition between business models. As the literature on business model innovation suggests, questioning the current business model, and going through trial and error processes to modify it, constitutes without doubt a trigger for change, on the one hand, but it also brings along potential negative consequences, such as higher levels of uncertainty, rising complexity and spirals of conflicts and 
mistrust (Massa and Tucci 2013). If this is true for organizations, it can be even more so for cross-sector inter-organizational partnerships that entail high levels of uncertainty, complexity and conflictuality per se. Our case study testifies the thin line between questioning the actual business model, innovating it, and declaring the failure of the partnership. For instance, we have shown that in the transition stage, partners' problems with the business model led them to experience a generalize state of paralysis in decision making and project management, which almost caused the dissolvement of the partnership. It was only thanks to the presence of some catalyzing factors -i.e., pressures to avoid failure, persisting need to accomplish the goals that brought them in the partnership in the first place, compulsion to complete the initiated collaboration- that partners decided to keep looking for alternative solutions. However, in cases in which these catalyzing factors are missing or are less impactful, partners might decide to throw in the towel rather than sustain the efforts and uncertainties entailed by a new business model. The question that rises spontaneous is: Given the fragility of hybrid partnerships, especially in the beginning phases (Doz and Boburoglu 2000; Austin \& Seitanidi 2012), is it worthy to try a business model innovation if there are signs that the model in place is not performing well, or is it more convenient to try to ensure partnership stability and wait for the consolidation of the current model? Evidence from the literature suggests that the ability to continuously adjust plays a very important aspect in the evolution of a partnership (Eden and Huxham 2001; Majchrzak et al. 2015). Future research might investigate when and whether small steps of business innovation can allow for swifter and less destabilizing translations (see also Sosna et al. 2010)

$\mathrm{Al}$ in all, ecosystems that encompass the public and the private domain develop around fuzzy sets of relations between multiple organizations with heterogeneous goals and interests (Hartley et al. 2013; Selsky and Parker 2005; Waddell and Brown 1997). 2000). Although interest in the nature, evolution, and conceptualization of hybrid partnerships has been remarkable, literature has shared a tendency to portray these forms of collaboration as win-win situations of which all stakeholders benefit (Austin and Seitanidi 2012; Linder and Rosenau). Yet little is known about business model adopting in such settings, and the logics and mechanisms that allow actors to innovate their business models (Clodia Vurro et. 2010; Dahan et al. 2010). Two business models of hybrid partnerships have been discussed in this chapter, the brokering model and the platform model. While the platform model seems more appropriate for complex projects in which heterogeneous cross-sector interests coexist, both models present advantages and disadvantages. We have suggested that attention should be given to identifying, signaling and managing both advantages and disadvantages in a relational manner, by focusing on how the business model innovation will impact on each parameter of the current model and, at the same time, on how manageable the parameters of the new model are in terms of partnership strategy, structure and mobilizable resources.

\section{References}


Amit R, and Zott C (2012). Creating value through business model innovation. MIT Sloan Management Review, 53(3), 41.

Arino A, and De La Torre J (1998). Learning from failure: Towards an evolutionary model of collaborative ventures. Organization Science, 9(3), 306-325.

Austin JE, and Seitanidi MM (2012). Collaborative value creation: A review of partnering between nonprofits and businesses. Part 2: Partnership processes and outcomes. Nonprofit and Voluntary Sector Quarterly, 0899764012454685.

Bernier L, and Hafsi T (2007). The changing nature of public entrepreneurship. Public Administration Review, 67(3), 488-503.

Bryson JM, Crosby BC, and Stone MM (2006). The design and implementation of crosssector collaborations: Propositions from the literature. Public Administration Review, 44-55. Casadesus-Masanell R, and Ricart JE (2010). From strategy to business models and onto tactics. Long Range Planning, 43(2), 195-215.

Cavalcante S, Kesting P, and Ulhøi J (2011). Business model dynamics and innovation:(re) establishing the missing linkages. Management Decision, 49(8), 1327-1342.

Chesbrough H (2010). Business model innovation: opportunities and barriers. Long Range Planning, 43(2), 354-363.

Chesbrough H, and Schwartz K (2007). Innovating business models with co-development partnerships. Research-Technology Management, 50(1), 55-59.

Commission of the European Communities. 2014. An introduction to EU Cohesion Policy 2014-2020 http://ec.europa.eu/regional policy/sources/docgener/informat/basic/basic 2014 en.pdf.

Dahan NM, Doh JP, Oetzel J, and Yaziji M (2010). Corporate-NGO collaboration: Co-creating new business models for developing markets. Long Range Planning, 43(2), 326-342.

Damanpour F, and Schneider M (2009). Characteristics of innovation and innovation adoption in public organizations: Assessing the role of managers. Journal of public administration research and theory, 19(3), 495-522.

Doz Y, and Baburoglu O (2000). From competition to collaboration: The emergence and evolution of R\&D cooperatives. Cooperative Strategy: Economics, Business and Organisational Issues, 173-192.

Eden C, and Huxham C (2001). The negotiation of purpose in multi-organizational collaborative groups. Journal of Management Studies, 38(3), 373-391.

Googins BK, and Rochlin SA (2000). Creating the partnership society: Understanding the rhetoric and reality of cross-sectoral partnerships. Business and society review, 105(1), 127 144.

Hartley J, Sørensen E, and Torfing J (2013). Collaborative innovation: A viable alternative to market competition and organizational entrepreneurship. Public Administration Review, 73(6), 821-830.

Hjorth D (2013). Public entrepreneurship: Desiring social change, creating sociality. Entrepreneurship \& Regional Development, 25(1-2), 34-51.

Hundal S (2014). The role partnership brokers play in creating effective social partnerships. Social partnerships and responsible business: A research handbook, 420

Jupp B. (2000). Working together: Creating a better environment for cross-sector partnerships (Vol. 23): Demos.

Kivleniece I, and Quelin BV (2012). Creating and capturing value in public-private ties: A private actor's perspective. Academy of Management Review, 37(2), 272-299.

Koschmann MA, Kuhn TR, and Pfarrer MD (2012). A communicative framework of value in cross-sector partnerships. Academy of Management Review, 37(3), 332-354.

Le Ber MJ, and Branzei O (2010). (Re) forming strategic cross-sector partnerships relational processes of social innovation. Business \& Society, 49(1), 140-172. 
Leitão J and Alves H (Eds.) (2016). Entrepreneurial and Innovative Practices in Public Institutions: A Quality of Life Approach, Applying Quality of Life Research: Best Practices, Springer.

Linder SH, and Rosenau PV (2000). Mapping the terrain of public-private policy partnership: Public-Private Policy Partnerships. Cambridge, Mass., MIT Press.

Lunnan R, and Haugland SA (2008). Predicting and measuring alliance performance: A multidimensional analysis. Strategic management journal, 29(5), 545-556.

Majchrzak A, Jarvenpaa SL, and Bagherzadeh M (2015). A review of interorganizational collaboration dynamics. Journal of Management, 41(5), 1338-1360.

Massa L, and Tucci CL (2013). Business model innovation. The Oxford Handbook of Innovafion Management, 420-441.

Mitchell D, and Coles C (2003). The ultimate competitive advantage of continuing business model innovation. Journal of Business Strategy, 24(5), 15-21.

Morris M, Schindehutte M, and Allen J (2005). The entrepreneur's business model: toward a unified perspective. Journal of Business Research, 58(6), 726-735.

Morris MH, and Jones FF (1999). Entrepreneurship in established organizations: The case of the public sector. Entrepreneurship: Theory and Practice, 24(1), 71-71.

Muscio A (2010). What drives the university use of technology transfer offices? Evidence from Italy. The Journal of Technology Transfer, 35(2), 181-202.

Romano A, Passiante G, Del Vecchio P, and Secundo G (2014). The innovation ecosystem as booster for the innovative entrepreneurship in the smart specialisation strategy. International Journal of Knowledge-Based Development, 5(3), 271-288.

Rondinelli DA, and London T (2003). How corporations and environmental groups cooperate: Assessing cross-sector alliances and collaborations. The Academy of Management Executive, 17(1), 61-76.

Selsky JW, and Parker B (2005). Cross-sector partnerships to address social issues: Challenges to theory and practice. Journal of Management, 31(6), 849-873.

Skelcher C (2005). Public-private partnerships and hybridity. The Oxford handbook of public management, 347-370.

Sosna M, Trevinyo-Rodríguez RN, and Velamuri SR (2010). Business model innovation through trial-and-error learning: The Naturhouse case. Long Range Planning, 43(2), 383407.

Teece DJ (2010). Business models, business strategy and innovation. Long Range Planning, 43(2), 172-194.

Turcotte M-F, and Pasquero J (2001). The paradox of multistakeholder collaborative roundtables. The Journal of Applied Behavioral Science, 37(4), 447-464.

Vurro C, Dacin MT, and Perrini F (2010). Institutional antecedents of partnering for social change: How institutional logics shape cross-sector social partnerships. Journal of Business Ethics, 94, 39-53.

Waddell S, and Brown LD. (1997). Fostering intersectoral partnering: A guide to promoting cooperation among government, business, and civil society actors (Vol. 13): Institute for development research (IDR).

Warner M (2003). Partnerships for sustainable development: Do we need partnership brokers. ODI, London.

Zerbinati S, and Souitaris V (2005). Entrepreneurship in the public sector: a framework of analysis in European local governments. Entrepreneurship \& Regional Development, 17(1), 43-64.

Zott C, Amit R, and Massa L (2011). The business model: recent developments and future research. Journal of Management, 37(4), 1019-1042. 
Charlton BG, and Andras P (2005). "Universities and social progress in modernizing societies: how educational expansion has replaced socialism as an instrument of political reform". Critical Quarterly, 47(1-2), pp. 30-39.

Chrisman JJ, Hynes T, and Fraser S (1995). 'Faculty entrepreneurship and economic development: The case of the University of Calgary'. Journal of Business Venturing, vol. 10, no. 4, pp. 267-281.

Clark BR (1998). 'Creating entrepreneurial universities'. Oxford: Pergamon.

Coduras A, Levie J, Kelley D, Sæmundsson R, and Schøtt T (2010). 'Global Entrepreneurship Monitor special report: A global perspective on entrepreneurship education and training'. Massachusetts: Babson College.

Corbett A, and Katz JA (2012). 'Introduction: The action of entrepreneurs', In Andrew C Corbett, Jerome A Katz (eds.): Entrepreneurial action (Advances in entrepreneurship, firm emergence and growth, Volume 14), Emerald Group Publishing Limited.

Freeman RB (1996). 'Working for nothing: The supply of volunteer labor'. National bureau of economic research, Research paper No 423WP.

Guerrero M, Urbano D, and Salamzadeh A (2013). 'Evolving entrepreneurial universities: Experiences and challenges in the Middle Eastern context', In Fayolle A, and Redford D, Handbook of Research in Entrepreneurship Education, Volume 4 - Entrepreneurial University Handbook. Edward Elgar.

World Economic Forum (2011). Global Competitiveness Report 2011-2012. Centre for Global Competitiveness and Performance, Geneva: World Economic Forum.

Wright M, Clarysse B, Mustar P., and Lockett A (2007). 'Academic entrepreneurship in Europe,' Massachusetts, U.S.: Edward Elgar Publishing. 